\title{
Arterialized blood from a central venous catheter after cardiac surgery: a puzzle for the intensivist
}

\author{
Michal Lips, MD • Vladimir Cerny, MD • Martin Balik, MD, PhD • \\ Michal Porizka, MD, PhD $\mathbb{D}$
}

Received: 26 January 2018/Revised: 12 February 2018/Accepted: 12 February 2018/Published online: 27 February 2018

(C) Canadian Anesthesiologists' Society 2018

A triple-lumen, 18G, 16-cm-long central venous catheter (CVC) was placed into the right internal jugular vein in a 74yr-old female undergoing elective annuloplasty of the mitral and tricuspid valves to treat severe regurgitation from mitral anterior leaflet prolapse and tricuspid annular dilatation. After uneventful surgery, simultaneous blood samples were drawn from the radial artery and distal lumen of the CVC for blood gas analysis. Surprisingly, central venous blood analysis showed high oxygen saturation $(96 \%)$ and partial pressure of oxygen $\left(\mathrm{PvO}_{2}=84 \mathrm{mmHg}\right)$ similar to the sample taken from the arterial catheter $\left(98 \% ; \mathrm{PaO}_{2}=122 \mathrm{mmHg}\right)$. The central venous pressure at the time of the blood draw was $9 \mathrm{mmHg}$. A

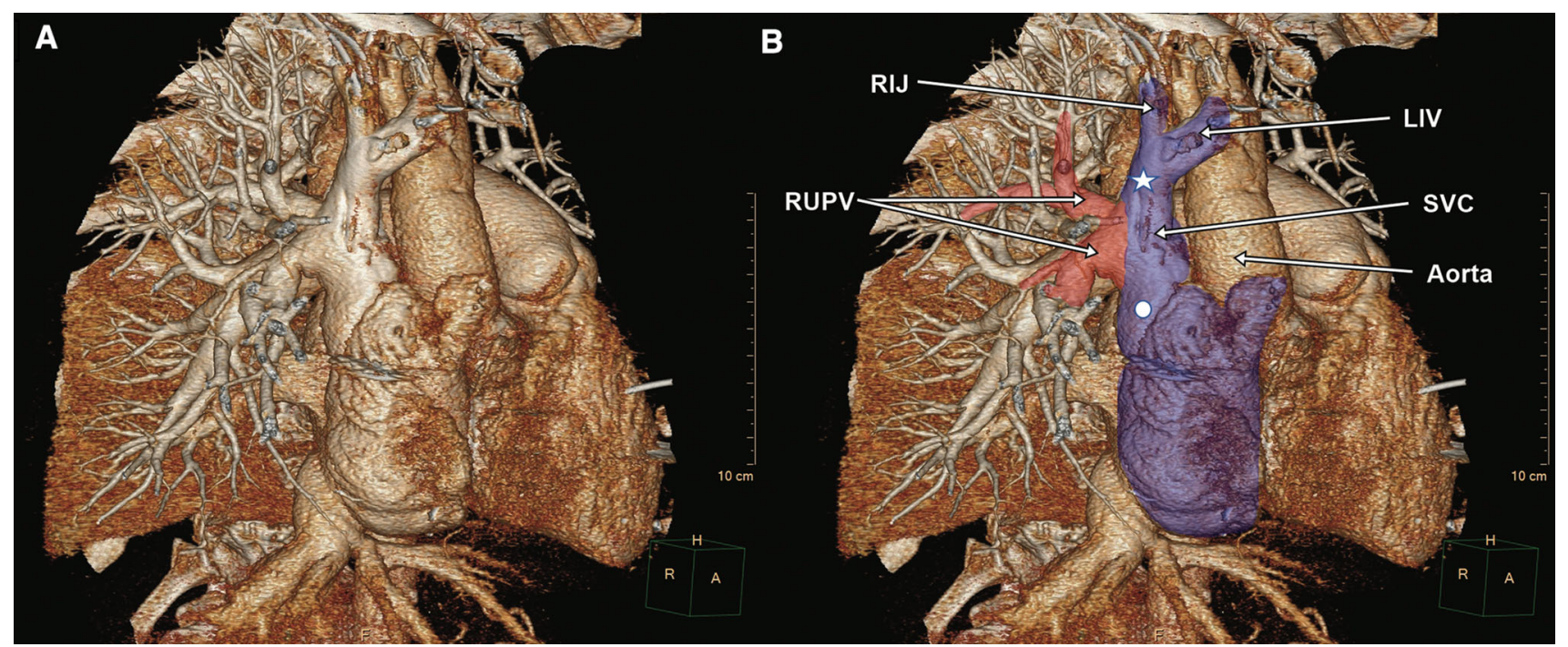

Figure (A) Three-dimensional reconstruction of a chest computed tomography angiogram. (B) The red-coloured area highlights the two branches of the anomalous right upper pulmonary vein (RUPV) entering the superior vena cava (SVC), which together with the innominate vein and right atrium are highlighted in blue. The proximal port of the central venous catheter (CVC) is indicated by the white star and the distal port by the white dot. LIV = left innominate vein; RIJ = right internal jugular vein. The images were used with the patient's permission
M. Lips, MD · M. Balik, MD, PhD · M. Porizka, MD, PhD ( $ه)$ Department of Anaesthesiology, Resuscitation and Intensive Medicine, First Faculty of Medicine, Charles University and General University Hospital in Prague, Prague, Czech Republic e-mail: rizko@post.cz

\section{Cerny, MD}

Department of Radiology, First Faculty of Medicine, Charles University and General University Hospital in Prague, Prague, Czech Republic 
postoperative chest radiograph showed the CVC in correct position with the tip of a catheter visible at the superior vena cava (SVC)-right atrial junction. Further blood sampling from the $\mathrm{CVC}$ showed a significant difference in oxygen saturation between samples from the proximal (64\%) and distal CVC lumen $(96 \%)$. Preoperative transthoracic and perioperative transoesophageal echocardiographic examination revealed no atrial septal defect or other obvious pathology explaining the left-to-right blood shunting. Although moderate dilatation of the right heart chambers was seen on echocardiography, it was considered non-specific and consistent with the known valvular pathology. Subsequent postoperative computed tomography angiography confirmed partial anomalous pulmonary venous drainage with two branches of the right upper pulmonary vein entering the SVC (Figure). The diagnosis warrants long-term follow-up to detect the possible development of severe pulmonary hypertension and right ventricular dysfunction that might be prevented by a surgical correction.

Conflicts of interest None declared.

Editorial responsibility This submission was handled by Dr. Hilary P. Grocott, Editor-in-Chief, Canadian Journal of Anesthesia. 